\title{
THE CONDITIONS OF FATIGUE IN THE NERVOUS SYSTEM. ${ }^{1}$
}

\author{
BY WILLIAM MCDOUGALI, M.A., M.B.
}

OUr English word "fatigue" is a most comprehensive one. Wherever there is evidence that organic activity results in diminished capacity of the organism to carry on any of its functions, there we commonly recognize fatigue. Such evidence is of two kinds, objective and subjective. Of the subjective symptoms we must distinguish at least three classes :-

(1) Local sensations of fatigue, more especially in the muscles.

(2) The sense or feeling of general tiredness, of limpness and general incapacity for effort.

(3) The experience we call sleepiness.

The first of these I dismiss with a single observation You may get this sensation of local fatigue in the acutest form by holding out a limb - say, the arm-for a few minutes against the pull of gravity. After a few minutes you begin to experience in the muscles of the shoulder a disagreeable sensation, which grows rapidly more intense, until; after about five minutes, you feel that you can hardly support it. But, if you persevere, you find that there is no impossibility about doing so; the disagreeable or painful sensation grows but little more intense, if at all, after the first few minutes; you may continue to hold out your arm, and, after half an hour, there will be little more discomfort than after five minutes.

Put alongside that the fact that most good hypnotic subjects will, when in hypnosis, keep a limb held up against the force of gravity for long periods without showing any tendency to relex it, or any other symptom of fatigue.

Facts of this order seem to show clearly that such local fatiguesensation is protective in function; that in sets it long before there is

1 The ideas set forth in this paper were embodied in an address to the Physiological Section of the British Association at the Dublin meating in the year 1908. That address was printed in the Reports of the Association, but I have sought from tho editor of this journal the opportunity of bringing my idess more prominently before the medical world by publication in these pages. 
any question of exhanstion of, or serious injury to, the tissues concerned through over-action. They show that the organism has need of some protection against the possibility of self-injury through excess of activity.

And this conclusion may serve to direct our attention to the possibility of a similar function being performed by other manifestations of fatigue.

In connection with the two other classes of subjective symptomstiredness and sleepiness- I would draw attention to experiences of a kind that are familiar to all of us. I sit reading in the evening some difficult technical work, until, as midnight approaches, I feel thoroughly tired and sleepy, my eyes smart and will hardly keep open, my head is dull and heavy and aches a little, my whole body and my limbs feel heavy and incapable of alert movement. I then take up some thrilling story or other fascinating piece of literature; whereupon all my subjective symptoms of fatigue, both tiredness and sleepiness, disappear, and I read keenly for perhaps two hours; when I again begin to feel both tired and sleepy. Now suppose a continuation of the evening's history which is less familiar : some exciting event takes place just as I' am about to go to bed-the house takes fire, or a burglar breaks in, or a friend comes in with important and interesting news that demands immediate action. Again all the symptoms of fatigue disappear, and I can perform another spell of work at high pressure, without subjective symptoms, and with little, if any, objective trace of fatigue, i.e., without easily appreciable diminution of efficiency.

Facts of this order show clearly, I think, that what we commonly call fatigue, with all its diverse symptoms, objective and subjective, is no entity, that it is not due to any one kind of change in the organism; and they show that fatigue is never absolute, but is always relative. That is to say, the symptoms of fatigue are always the expression of the relation between at least two things-between, on the one hand, the work to be done, and, on the other hand, the amount of energy available at the moment for doing the work; or, in more technical language, the symptoms of fatigue are the expression of a change in the ratio between the available energy (the energy in an active living state at the moment) and the resistance which that energy has to overcome. If the task in hand is intrinsically uninteresting, the energies brought into play, liberated within the organism, or transformed from the potential to the active state, are small in quantity; therefore a small amount of work, producing a small increase of the resistances to be overcome, suffices to raise the ratio of resistances to energies above the normal, and, therefore, 
to produce the symptoms of fatigue; whereas, if the circumstances are such as to bring into play greater stores of the potential energy of the organism, a much greater amount of work may be done by the organism (whether bodily or mental work), before the ratio of the resistance to the available energy rises to the point at which symptoms of fatigue appear.

Reflection upon these familiar experiences yields then two propositions which, I believe, may be two master-keys to all the problems. of fatigue-at any rate, to those of fatigue of the nervous system. They may be briefly stated as follows:-

(1) Fatigue of the nervous system is a state in which the ratio of the resistances to the active energies is raised above its normal value, either through increase of the magnitude of the resistances or through diminution of the quantity of disposable energy.

(2) The function of the resistances is essentially the limitation of activity: they are thus protective of the energy of the organism; they prevent the organism exhrusting its store of potential energy through unduly prolonged, intense, or widespread activity.

If these propositions are well founded we must, in order to understand fatigue, have good working conceptions on the one hand of the sources of the energies concerned and of the conditions and nature of their operations in the nervous system, and on the other hand of the nature and seat of the resistances that limit and preserve these energies.

It has recently been contended, notably by Bethe [1] in Germany and by Deschamps [2] in France, that the nervous system is not the seat of the liberation of any energy, or at any rate that such liberation is no part of its specific functions, but that it merely distributes the active energies supplied to it by stimuli of all kinds and by the various organs of the body. I think most physiologists will hold that this view is quite unacceptable, and that the activity of the central nervous system does essentially and always involve liberation of energy, transformation of energy from the potential to the active form, and a consumption or using up of stores of potential energy. Verworn [9], who has made himself the protagonist of this latter view, seems to me to have proved it by his own experiments and those of his papils, although, even without these particular experimental results, there was hardly room for doubt about the matter. Further, Verworn's experiments on the spinal cords of frogs confirm the view (about which also there was little room for doubt apart from these experiments) that fatigue may be produced by either of two processes, and that it commonly is produced 
by their conjunction-namely, (1) the process of accumulation of waste products of metabolism, $\mathrm{CO}_{2}$, lactic acid and other substances; (2) the using up of stores of potential energy through excess of katabolism over anabolism. The former is called by the Germans "Ermüdung," the latter "Erschöpfung," and some English writers have proposed to use the words fatigue and exhaustion in these two senses, as the equivalents of these German words. I do not think we can profitably specialise these words in this way ; ${ }^{1}$ but, if not, we must have new words, for there can be little doubt that both processes take part in the production of fatigue, and we must distinguish between them and hold fast the two conceptions.

The question then arises- What are the seats within the nervous system of these two processes, "Erschöpfung" and "Ermüdung"? Verworn's view may perhaps claim the adherence of a larger number of physiologists than any other. It is very simple. According to this view, the cell-bodies or "ganglion cells" are the seats, or at least the principal seats, of both processes; and of both processes the essential result, which determines all the symptoms of fatigue, is a diminished katabolism and output of energy by the cell-bodies affected. " Erschöpfung" is thus, according to this view, a strictly local process, affecting only the bodies of the nerve-cells involved in any activity; while "Ermüdung" is both local and general, because the cell-body is liable to be poisoned not only by the waste products of its own activity, but also by those of the metabclism oi other nerve-cells and of other tissues of all parts of the body, especially the muscular tissues; for these waste products, wherever formed, may pass into the blood and lymph and so nay reach the "ganglion cells."

Now I venture to say that this picture of the nature of fatigue of the nervous system is very much too simple; the conceptions are, I contend, true and useful, but inadequate to the explanation of the complex manifestations of fatigue which meet us as soon as we consider the organism as a whole; and they are inadequate also for the explanation of many of the special and local manifestations of fatigue.

The picture needs, it seems to me, to be complicated by two most important additions. First, Verworn's scheme takes little or no account of the resistances that the nervous energies have to overcome. Now, if with him we regard the cells as seats of explosive decompositions, and

\footnotetext{
"Because we noed the word "fatigue" to denote the state of diminisbed efficiency of the organism as a whole comthonly produced by these two processes in conjunction, and we need the word "exhaustion" to denote the extreme degree of the state resulting from excess of katabolism over anabolism.
} 
the nerve-fibres as freely conducting excitations (either purely physicar processes or, with more probability, as physico-chemical processes involving metabolic changes similar to those that occur in the cell bodies), then it is obvious that there must be points or parts of the nervous tracts which delimit functional units and groups of units; else, instead of the orderly sequence of nervous excitations, which normally results from any stimulation, the excitation would spread indefinitely throughout the nervous system, soon producing incoördinate general activity and a rapidly ensuing general exhaustion; in the way the results of which we see in the convulsions of strychnine poisoning.

Now the question, Where, in what structures, do these resistances reside? is one of secondary importance perhaps, so long as we recognize their nature and function. Still it is a question of some interest. In a recent paper Verworn recognizes the existence of resistances, and assigns them, like all the other peculiarities of the central nervous system, to the cell-bodies [10]. To that view serious objections may be raised. To mention only one, it is difficult to suppose that the cellbodies are the seats both of explosive decompositions that liberate energy and also of the resistances that delimit the paths by which the excitation spreads towards the efferent nerves. On the other hand, there are many considerations tending to show that the principal seats of these resistances may be the synapses or places of junction of the neurones. ${ }^{1}$

If we assume that the synapses are the seats of the resistances, and that the process of transmission of the impulse across the synapse is one that results in a temporary raising of the resistance of the synapse, then we have a conception which enables us to account satisfactorily for many manifestations of fatigue. I will point out a few of the facts

\footnotetext{
I See especially Sherrington's "Integrative Action of the Nervous System," Lecture I. In spite of all that has been written of the synepse in recent yesrs, one still finds widely accepted the following argument: The nervous system consists of cell-bodies and nervefibres, therefore all those of its properties that are not displayed by peripheral nerves are due to the cell-bodies. Verworn bimself still uses this argument, and so little is the conception of the symapse understood that Verworn, in a recent paper, interprets Sherrington as meaning by the torm "synapse" the place of junction of the axis cylinder and the cell-body of a gingle neurone. That, I take it, is implied when be writes, "Goldsoheider und Sherrington denken an die Uebergangstelle des Nerven in den Ganglionzellkörper, an die 'Synapse,' wie Sherrington sich ausdrückt" (Op. cit., p. 194). Sherrington inclines to the view that tho process of transmission of the excitation across the synapse is a purely physical one (Op. cit., p. 17); but if, as he also inclines to believe, it is a process very readily affected by the prasenco of toxic substances in the blood, and if it bas the effect of immediately and temporarily rnising the synaptic resistance (fatigue), and of ultimately leaving it (when the fatigue effect has passed away) permanently diminished (habit), these effects would seem to demand for their explanation the assumption of some metabolio activity at. the syndpse. In a paper in Brain (vol. xriv.) I have adduced other arguments in support of the assumption of intercellular substances, the seats of synaptio metabolism of a highly speoialized kind.
} 
which seem to point to the synapse rather than to the cell-bodies as the principal seats of the increased resistance. It has long been notorious that nerve-fibres are but little, if at all, liable to fatigue; and there is good reason to believe that the cell-bodies also are fatigued, not easily or rapidly, but only under prolonged activity or when-deprived of the normal means of recuperation-deprived, that is, of the normal blood-supply. Yet we have evidence that local fatigue may be rapidly induced, and may as rapidly pass away, in the various levels of the nervous system.

Such local fatigue occurs in the reflex arcs of the spinal cord, if a stimulus is continuously applied to the afferent path [8]. It occurs in the motor region of the cerebral cortex if one spot be continuously or repeatedly stimulated [4]. It occurs still more readily in the higher levels of the brain concerned in perception-e.g., in all the cases of ambiguous figures which may be perceptually interpreted in two or more different ways, and of which the different modes thrust themselves alternately upon consciousness. I have studied these alternations and shown reason to suppose that a rapidly induced local fatigue of the higher cortical paths concerned is the principal condition of this alternating activity [5]. In the same way the extreme liability to fatigue of the paths of the higher cortical levels seems to underlie the extreme instability of all our thought processes; the fact that our attention can never be held fixedly and unchangingly upon any single feature of an object, but always, in spite of all voluntary efforts to the contrary, passes on from feature to feature, or plays to and fro over the object of thought.

In all these cases we seem to be dealing with a rise of the resistance of a nervous path rapidly induced by its activity and as rapidly passing away; a rise of resistance which serves to divert the excitation-process from the path to some other channel, and so to prevent the injurious effects of a too-prolonged activity of any one path.

These are manifestations of local fatigue, of increase of the ratio of resistance to energy, induced not by diminution of energy, but by increase of strictly local resistance.

Again, experiments with the ergograph have been used much in the study of fatigue, but one interesting feature of such experiments has been unduly neglected, I think. I draw attention to it in this connection, because it seems to bear out the view I am setting forth.

The subject of the experiment has to lift a heavy weight repeatedly at brief intervals, by bending as far as he can his middle finger. Fatigue very soon manifests itself in the form of a diminished extent of the bendings 
of the finger. Now, if you carefully observe the subject as he continues to repeat his efforts, you will usually see that, while at first he contracts only the muscles immediately concerned in the flexion of the finger, other muscles come into play as the flexions become diminished in extent; first the muscles of the upper arm, then those of the shoulder, then those of the trunk, still later the muscles of the lower limbs and of the arm and shoulder of the opposite side, and even those of the face, jaw, and neck on both sides. There takes place, in short, a spread or march of the excitation (not unlike the march of Jacksonian epilepsy) from the motor tract directly concerned in producing the flexion of the finger to adjacent motor tracts, then to successively more distant tracts.

Now this is just what must occur if, while the supply of liberated nervous energy is maintained at a high level of potential, and while the subject continues to direct it towards the one set of muscles, the resistances of the paths through which the excitation reaches those muscles are liable to be rapidly raised owing to the intensity of the process and to its repetition at brief intervals. The excitation will overflow, first into the most nearly connected tracts; later into those successively more remote, as the resistances of the more nearly connected tracts become in turn increased.

A very brief rest suffices to abolish or to diminish in very large degree any fatigue symptoms induced by ergographic work; and if in the ergographic experiments the intervals between successive bendings of the finger are made equal to several seconds, the evidences of fatigue are mach diminished.

We have then abundant evidence of the rapid production of local increase of resistance in the central nervous system, and all that we know of the cell-bodies and of the axis cylinders malies it improbable that they can be the seats of these rapidly induced and very transitory local increases of resistance. Further, the fact that these local increases of resistance seem to be most rapidly induced in the higher levels of the central nervous system, where the connections between neurones must be regarded as least intimate and fixed, and to be least rapidly induced in the reflex arcs of the spinal cord, where the connections between afferent and efferent neurones are most firmly established, is in harmony with the view I am defending, and seems unintelligible if the alternative view is adopted.

It seems probable that the resistance of the synapses is liable to be temporarily increased not only locally by the transmission of the nervous 
excitation across them, but also generally by the influence of the waste products of metabolism brought to them in the blood, for they seem to be easily affected by chemical influences of many kinds. ${ }^{1}$

If so, then such action of waste products upon them must play a large part in that general increase of the ratio of resistance to energy which constitutes general fatigue, and which manifests itself subjectively in general tiredness and in sleepiness; and also in the onset of sleep or general quiescence of the brain, the most important of the modes in which the organism protects itself against exhaustion.

If we provisionally accept this view, that the synapses are the principal seats of resistance, and that their resistances are liable to be thus increased both locally and generally, then the simple picture of fatigue which I have associated with the name of Verworn becomes considerably complicated. In addition to local "Erschöpfung" of the neurones, and to local and general "Ermüdung" of them by waste products, the former of which means local, and the latter both local and general, diminution of energy supply, we recognise both local and general increase of synaptic resistances. We have then, I think, $a$ scheme much less inadequate to the explanation of those familiar and important peculiarities of fatigue to which attention was drawn in the opening paragraphs.

But there were, I said, two complications to be added to the simple Verworn picture. We have added the resistances varying from local and from general causes. The second complication concerns the sources of the energies involved in bodily and mental activity.

According to the Verworn scheme every cell-body is, I take it, to be conceived as capable of generating or transforming or liberating a certain quantity of energy, which, up to a certain upper limit, varies with the intensity of the stimulus applied to the cell; and this energy is to be regarded as finding its field of operation wholly within the neurone or the particular small functional group of neurones within which it is liberated; and all neurones are of appreciably equal value in this respect.

But there is another conception of the mode of operation of nervous energy which goes back at least as far as Descartes; the conceptionnamely, that the energy liberated by chemical change, by katabolic process, in one part of the nervous system may be conducted through the nervous channels and may operate in other parts of the nervous system. This may be called the hypothesis of the vicarious usage of

1 There is something to be said for the view that they are the seats of the primary and principal influence of various drugs, possibly of alcohol, chloroform, strychuine, and others. 
nervous energy. Now it seems impossible to get the physiologists of the laboratory, the physiologists who are chiefly concerned with the organs rather than with the organism, to consider this conception seriously and on its merits. If they occasionally refer to it, it is only to put it aside contemptuously as a naïve survival from the dark ages. Yet those who are in the habit of dealing with the problems of the organism as a whole, the physician and the psychologist, constantly make use of this conception, for they find it impossible to make progress in the understanding of their problems without it. ${ }^{1}$ That fact gives the conception a claim to a more serious consideration than it has commonly received from the physiologists.

The conception towards which the study of the organism as a whole points is that the neurones of the afferent side of the nervous system (including the cerebellam) constitute a great common reservoir of free energy, in which the head of pressure varies from moment to moment with the ratio of the in-flow to the out-flow, and on which all efferent paths may draw in turn when they come into activity.

As to the sources from which this reservoir of free energy is supplied, no doubt every one of its constituent neurones is capable of making its contribution, and especially all those directly connected with, and stimulated through, the sense-organs.

But we shall never understand the problems of fatigue, or any other of the great problems of the brain, until we adequately recognise certain special sources of supply. And the study of fatigue serves to bring into prominence the importance of these special sources of energy.

In psychology we speak of instincts or innate dispositions to action, and we recognise that the constitation of every human being comprises a certain number of such instinctive dispositions, and that, when any one of these is awakened, whether by sense-impression or idea, the subject experiences a state of emotional excitement, and an impulse, a desire or aversion, a strong conation or felt tendency towards some kind of action. We recognise that under the driving power of such an impulse the subject can achieve tasks, can put forth quantities of energy, such as are impossible for him in the absence of any such conative-affective excitement. ${ }^{2}$

\footnotetext{
1 The necessity of conceiving nervous energy in this way was urged as loug ago as 1886 by Hale Wbite (Lancet, vol. ii., 1886, p. 161; seo also Brit. Med. Journ., October 17, 1908), who proposed to use the word "neurorrbeume" to denote nervous energy so conceived." Amoug many others who have approved of this conception are Victor Horsley (Hughlings Jackson Lecture, Brain, vol. xxix., p. 448), and S. G. Sharkey (Presidential Address to tho Neurologianl Society, Brain, vol. xxvii., p. 12).

$=$ For a fuller discussion of the role of these innate dispositions in the maintenance of human activities, I may refer to my Introduction to Social Pyschology.
} 
It is for the physiologist to discover, if possible, the neural seats and bases of these innate dispositions. Recent work by Pagano seems to indicate that they may perhaps be found in the basal ganglia of the brain $[6]$.

But however that may be, it seems safe to assume that these powerful impulses, which we experience in conjunction with our emotional excitements, and which enable us to energise in a way quite impossible in their absence, have nervons correlates, and that the physiological correlate of such an impulse is a great liberation of energy, in some centre or part of the central nervous system, which energy augmenting greatly the disposable free energy of the brain, can be utilised in the performance of any kind of action undertaken for securing the satisfaction of the impulse: and it seems that such an accession of energy can overcorwe the increased resistances obtaining in a state of modernte general fatigue, abolishing more or less completely in so doing both the objective and the subjective symptoms of fatigue; because the great accession of energy lowers the ratio of resistance to energy.

It is the possibility of these sudden accessions of energy that has rendered wellnigh futile all the many attempts hitherto made to obtain reliable objective measures of degrees of fatigne of the organism as a whole. ${ }^{1}$ Rivers [7] has recently shown how great a disturbing factor. in ergographic work is "interest," and the awakening of interest on the part of the subject means essentially the bringing into play of one or more of these special sources of energy.

Again, in such fatigue experiments as those of the Kraepelin school, the fatigue effects are constantly complicated, obscured, and rendered doubtful by variations of interest or of impulse which show themselves in spurts of all sorts. ${ }^{2}$

It is only when we take into account these special sources of energy that we can begin to understand the way in which, under circumstances that powerfully evoke our native impulses, we can execute without

'Binet and Henri have shown the inadequacy of the various methods employed previous to the date of publication of their work-La Fialigue Intellectuelle (1898); and in a recent critical study of the principal methods Ellis and Shipe (Anterican Journ. of Psychology) have arrived ut the conclusion that none of those investigated by them are reliable.

The Krnepelin methods, I may remark in passing, seek to avoid these disturbances by keeping interest at a miuimum. But the human subject is not easily kept in such a state, he will become interested, if only in the spprosching end of his task, and hence grent irregularities. In view of these diffioulties I have suggested a method of estimating fatigue, which follows the opposite principle and seeks to keop interest at a maximum throughout, the task set being of the nnture of a spriut; and I venture to think that this is the sounder and more bopeful prinoiple to follow : see "A New Method for the Study of Concurrent Mental Operations nad of Mental Fatigue" (British Journal of Psychology, vol. i.). 
fatigue tasks which in less favourable circumstances would render us prostrate with every symptom of fatigue.

James, in a recent lecture entitled the "Energies of Men" [3], has dealt, in his brilliant way, with this aspect of our problem; he brought forward many examples of the way in which, under conditions suited to bring their powers most fully into play and to sustain their interest at a maximum, men may achieve incredibly severe and sustained efforts. He quoted especially the case of Colonel Baird Smith, who conducted the siege operations before Delhi during the Sepoy Mutiny, showing how for months he hardly ate or slept, or rested in any way, but worked almost continuously at tremendous pressure without showing or feeling fatigue, and how then, when the end came, and the circumstances ceased to demand and excite his efforts, he collapsed, an inert, emaciated, almost lifeless invalid.

Such cases illustrate again my main points-namely, (1) that fatigue is protective; (2) that fatigue is relative, is the expression of a rise of the ratio between resistances and energies; and they show how, if the conditions are such as effectively to call into play all the great special sources of energy, this ratio may be kept from rising above the normal, until the whole organism approaches absolute exhaustion; whereas, on the other hand, under conditions of boredom, the ratio is very readily raised above the normal.

If, then, there is any truth in what I have said of these sources of energy and of the vicarious usage of energy, it follows that we have to recognize as a second condition of general fatigue, in addition to the presence of products of metabolism in the blood, a diminution of the disposable energy, due to a diminished metabolisin of the neurones in general and of these special sources of energy in particular; and the possibility of general fatigue of this natare is, I think, especially important from the point of view of the physician.

The long continuance of the chronic fatigues with which the physician so often has to deal seems to show that, in many cases at least, these are not toxic fatigues (the only kind of general fatigue admissible under the too simple Verworn scheme). It seems to imply the exhaustion of some of the sources of energy, which, rendering the maintenance of a due general pressure or potential of free energy impossible, canses the ratio of resistance to energy in all parts of the nervous system to remain at a high level.

In conclusion I would suggest that the conception of fatigue as an increased ratio of resistance to energy may possibly help us in arriving at an understanding of some nervous disorders. 
A due balance between resistances and energies is essential to health, and it seems possible a priori that the balance may be disturbed by disorder primarily affecting either factor.

Suppose that, as an innate constitutional peculiarity, the resistances are deficient relatively to the energies in an otherwise normal or wellendowed brain; we should expect to see the possessor of such a brain an excitable sensitive person who, the great protective system being deficient, easily works himself to the point of exhaustion; exhaustion rather than fatigue will be his peculiarity. $\mathrm{He}$ is readily provoked to a great and rapid output of energy, and his brain does not easily return to rest; general excitement is slow to die away, and he finds difficulty in sleeping after any effort, for the condition of increased and predominant resistance throughout the brain is not easily attained; the system remains uselessly at work and wears itself out: there follows exhaustion secondarily developed, owing to the deficiency of the protective system of resistances. We should then get the typical picture of the hereditary or born neurasthenic; the disorder is bronght on by any strenuous course of life, and its early stages are characterized by hyperesthesias of all sorts, undue sensitiveness to all sense-impressions, general irritability or irritable weakness, insomnia, increased reflexes; the patient may have the power of working extremely effectively for a short time, but such work soon leads to exhaustion and leaves the patient incapable for a long time of again getting up a sufficient head of nervous pressure to renew his labouts. It is, I think, in harmony with this view that some of our most brilliant and original intellects have shown marked neurasthenic tendency, e.g., Charles Darwin and Herbert Spencer.

The neurasthenia induced by shocks-e.g., the mental and physical shocks of a railway accident-may possibly be brought into line by the supposition that the brief and general over-stimulation of the nervous system, which was too sudden to allow the increase of resistances to play its normal protective part, has more or less paralysed the synupses, so that they no longer are capable of building up and maintaining the due resistances; and again initable weakness dominates the scene.

In this way it seems to me we nay perhaps account for the paradoxical character of neurasthenia, for its combination of excess and defect of energy, the difficulty of getting up steam, the easy and rapid running down of the effort, if an effort is successfully initiated.

There is another great type of functional disease-hysteria, so like and yet so different from neurasthenia, which seems to be also a form of chronic fatigue. 
Here possibly the primary evil is a constitutional defect of the energies relatively to the normal resistances. Such relative defect is apt to be brought to light by any course of life that makes considerable demands on the nervous energies, and shows itself in the failure to maintain the unitary functioning of all the many neural systems and sub-systems that make up the brain. The systems tend to become functionally separated from one another, because the supply of energy is insufficient to overcome the resistances of the highest levels of the brain and to keep open the connecting channels; hence each neural system tends to function independently of the rest, and each, being removed from the reciprocal control and inhibition normally exerted by all the rest, may function in excess, or, on the other hand, may lie dormant. Hence we get the curious pictures of overactions combined with partial defects of action, of hyperæsthesin with anæsthesia, of local contracture and paralysis, of incapacity for effort and violent convalsions, of fixed ideas and of easily changed convictions, of extreme suggestibility and extreme obstinacy. We get the characteristic symptoms of mental dissociation, ${ }^{3}$ and in extreme cases we get the falling asunder of the neural basis of unitary personality into two or more functional systems, each of which becomes more or less fixed in its isolation; and we thus get the most strange of all the functional disorders-the cases of divided or multiple personality.

\section{REFERENCES}

[1] Beтнe. "Zur Theorie der Zentrenfunktionen," Ergeb. der Physiol., Bd. v.

[2] Deschasp8. " Les Maladies de l'Energie," Paris, 1908.

[9] Jaмk8. "The Euergies of Man," Plitlosophical Rev., 1907.

[4] Lerr. "An Attempt to Estimate Fatigue of the Cerebrnl Cortex," Journ. of Physiol., vol. xxvi.

[5] MoDodgall. "Physiological Fractors of the Attention Process," Mind, N.S., vol. xv., p. 340.

[6] Pagavo. Archiv. Ital. de Biol., 1906.

[7] Rivers. "The Influence of Aloohol and other Drugs on Fatigue," London, 1908.

[8] Shenrinaton. "The Integrative Action of the Nervous Sfstem," London, 1906.

[9] Verwors. "Die Vorgānge in den Elementen des Nervensystems." Zeitschr. f. Allg. Physiol., Bd. vi.

[10] Idem. "Die cellalar physiologische Grundlage des Gedïchtnisses," Zeitschr. f. Allg. $P h_{\text {lysiol. }}$, Bd. vi.

I In this oonnexion I would refer the reader to my artiole "The state of the Brain during Hypnosis" in vol. xxxi. of this Journal. 